\title{
At a crossroads to cancer: How p53-induced cell fate decisions secure genome integrity
}

\author{
Dario Rizzotto ${ }^{1}$, Lukas Englmaier ${ }^{1,2}$ and Andreas Villunger ${ }^{1,2,3,4}$
}

${ }^{1}$ CeMM Research Center for Molecular Medicine of the Austrian Academy of Sciences, 1090 Vienna, AT;

${ }^{2}$ Ludwig Boltzmann Institute for Rare and Undiagnosed Diseases (LBI-RUD), 1090 Vienna, AT;

${ }^{3}$ Division of Developmental Immunology, Biocenter, Medical University of Innsbruck, Innsbruck, AT;

4Institute for Developmental Immunology, Biocenter, Medical University of Innsbruck, Innrain 80, 6020 AT, Innsbruck, Austria

* Correspondence: Andreas Villunger, PhD; andreas.villunger@i-med.ac.at

\begin{abstract}
Abstrac: P53 is known as the most critical tumor suppressor and is often referred to as the guardian of our genome. More than 40 years after its discovery, we are still struggling to understand all molecular details on how this transcription factor prevents oncogenesis or how to leverage current knowledge about its function to improve cancer treatment. Multiple cues, including DNA-damage or mitotic errors, can lead to the stabilization and nuclear translocation of p53, initiating the expression of multiple target genes. These transcriptional programs may well be cell type and stimulus-specific, as is their outcome that ultimately imposes a barrier to cellular transformation. Cell cycle arrest and cell death are two wellstudied consequences of p53 activation, but, while being considered as critical, they do not fully explain the consequences of p53 loss-of-function phenotypes in cancer. Here, we discuss how mitotic errors alert the p53 network and give an overview on multiple ways how p53 can trigger cell death. We argue that a comparative analysis of different types of p53 responses, elicited by different triggers in a time-resolved manner in well-defined model systems is critical to understand cell type specific cell fate induced by p53 upon its activation, in order to resolve the remaining mystery of its tumor suppressive function.
\end{abstract}

Keywords: p53; genomic instability; cell death

Abbreviations used

\begin{tabular}{cc}
\hline BH & BCL-2 homology \\
\hline CiC & cell-in-cell structure \\
\hline CIN & chromosomal instability \\
\hline DD & death domain \\
\hline DDR & DNA damage response \\
\hline DR & death receptor \\
\hline MEF & mouse embryonic fibroblast \\
\hline PTM & post-translational modifications \\
\hline RBP & RNA binding proteins \\
\hline SAC & spindle assembly checkpoint \\
\hline TNFR & tumor necrosis factor receptor
\end{tabular}




\section{Introduction}

Despite decades of research, cancer remains one of the leading causes of death worldwide and particularly in developed countries its incidence is still on the rise. Cancer arises usually upon long latency in response to a series of genetic alterations, triggered by exogenous (environmental exposition) and endogenous causes (genetic predisposition) that are additionally modulated by pathobionts, such as bacteria or viruses, making it very difficult to predict the time of its occurrence, its clinical progression and treatability [1-6].

However, neoplastic cells originating from different tissues often display similar molecular features, for example, the overexpression or mutation of proto-oncogenes, such as MYC or RAS, or the inactivation of tumor-suppressor genes. Perhaps the most common gene of this kind which is inactivated or lost in human cancers is TP53 (herein, p53). Nearly all the events currently known to compromise the genomic integrity of the cell (thus being potential drivers of transformation) can lead to p53 activation. This requires protein stabilization, accumulation and translocation into the nucleus, where p53 can elicit its function as a sequence-specific transcription factor [7]. Moreover, direct cell deathpromoting effector functions have also been proposed and will be discussed later.

Stunningly, despite extensive research into its biology and more than 100.000 papers cited in PubMed, we still fall short in understanding how p53 actually prevents cancer and how we could exploit current knowledge therapeutically.

The two best-studied cellular responses controlled by p53 are cell cycle arrest and the induction of apoptosis, that both aim to preserve genomic integrity for tissue homeostasis [8-11]. Indeed, active p53 promotes the transcription of $C D K N 1 A$, the gene encoding the potent Cyclin-dependent kinase inhibitor p21[12], and several genes encoding proteins involved in regulating mitochondrial and death-receptor driven apoptosis $[8,13]$. Yet, cell cycle arrest and apoptosis are only two of the many tumor-suppressive functions controlled by p53 [14-16]. Consistently, impairing the ability of p53 to activate $p 21$ and its apoptotic effectors does not impair its ability to suppress cancer $[17,18]$. This suggests additional mechanisms at play, likely those reducing the mutational burden and the maintenance of genome integrity $[8,19,20]$. Yet, alteration or loss of either of these effector arms can contribute to tumorigenesis as well as drug resistance phenotypes, as documented in multiple studies [21-26].

The importance of p53 in maintaining genome integrity becomes clear when looking at malignant cells in which the transcription factor is lost, mutated or inactivated. Indeed, a common feature of these cells is genomic instability, which is reflected by the increased accumulation of alterations at different levels, from mutations of the genetic sequence to alterations in chromosomes' structure and number [27]. Alterations noted at the level of the chromosomes are summarized as "chromosomal instability" (CIN) or, upon fixation, aneuploidy. CIN arises from errors during the mitotic process, caused by defects in checkpoints controlling mitotic entry, regulated by checkpoint kinase 1 (CHK1) [28], or mitotic exit, controlled by the E3-ligase, APC/C and its activator CDC20, as well as the spindle assembly checkpoint (SAC), ensuring the integrity of kinetochore-microtubule attachments in prometaphase [29,30]. Moreover, errors in centrosome biogenesis and number can also foster CIN, e.g. during multipolar mitoses [31-34]. Impairment of any of these control 
mechanisms can cause the missegregation of chromosomes into daughter cells, resulting in aneuploidy, an ultimately fixed abnormal number of chromosomes deviating from the physiological karyotype [35]. CIN and aneuploidy are interconnected [27] and they contribute to increasing intra-cancer heterogeneity, which in turn can confer a selective advantage, for example, in the development of resistance to conventional or targeted therapies [36,37]. Nonetheless, aneuploid cells often show initially decreased fitness, proteostasis and proliferation defects, together with an increased susceptibility towards cell death [38-40]. This suggests that aneuploidy might be beneficial only in certain contexts after sampling the right set of chromosomes allowing survival and outgrowth of cells with complex karyotypes. Hence, aneuploidy is often considered a rather late event in tumorigenesis, driving cancer evolution, but may not necessarily be responsible for tumor initiation $[31,36]$. Yet, this is an ongoing debate [38].

\section{How 553 puts the break on CIN and aneuploidy}

CIN and aneuploidy are frequently preceded by defects in cytokinesis, referring to the process allowing the mother cell that has duplicated its genome to physically separate into the two daughter cells at the end of mitosis [41,42]. In this situation, the cell undergoes wholegenome duplication, most commonly leading to tetraploidization [42]. It is believed that tetraploidization is an early event occurring in many cancers [43], which can foster CIN and aneuploidy in subsequent rounds of cell division. Moreover, tetraploid cells are more tolerant to chromosome loss compared to the diploid counterparts and consequently being more "fit" to undergo cancer-promoting alterations [36]. Another consequence of cytokinesis failure is the acquisition of extra centrosomes [44], which are the microtubule-organizing centers (MTOCs) responsible for generating the mitotic spindle during prophase [45]. In mitosis, the presence of extra centrosomes can lead to multipolar cell division, which are highly error prone $[9,44]$ due to frequent merotelic kinetochoremicrotubule attachments [44]. Not surprisingly, extra centrosomes are frequently seen in cancer lesions and are also discussed to increase the invasiveness of tumor cells [46,47].

Remarkably, p53 signaling can halt cells harboring an altered centrosome number as well as cells experiencing problems during mitosis that primes them for chromosome missegregation [48]. As an example, extended mitotic duration due to persistent activation of the SAC, which senses unattached kinetochores not bound to the mitotic spindle, can trigger a p53-dependent cell cycle arrest [49-51]_(Figure 1). This mechanism relies on 53BP1 and USP28 that stabilize p53 by removing ubiquitination performed by MDM2, the main E3-ligase controlling p53 protein levels. This allows its accumulation and the induction of p21, arresting the cell in the next G1 [49-51]. Of note, the quality of this type of p53 response is expected to differ from the one induced upon DNA damage, where 53BP1 is known for rapidly accumulating on chromatin at the sites of double-strand breaks and providing a scaffold for factors involved in DNA repair [52]. Under these conditions, p53 stabilization depends primarily on post-translational modifications (PTMs) mediated by kinases of the DNA damage response (DDR) pathway, such as ATM, ATR, CHK1 and CHK2, that phosphorylate p53 on specific N-terminal amino acid residues (e.g. Ser15, Ser20 and Ser37) [53,54], leading to the displacement of MDM2 for p53 stabilization (Figure 1). In the context of DNA damage, 53BP1 has a crucial role in directing non-homologous end 
joining or homologous recombination to remove double strand breaks [52,55]. Despite its name (p53 Binding Protein 1) and the presence of a Cterminal domain that can actually interact with p53, the importance of the interaction between p53 and 53BP1 remained uncertain [52]. More recently, it has been demonstrated that 53BP1, in concert with USP28, directly tunes p53 transcriptional activity in response to DNA damage independently of its function in promoting DNA repair [56]. Nevertheless, 53BP1 KO as well as USP28 KO cells retain p53 stabilization in response to the DNA damage-inducing agent doxorubicin, while phosphorylation of p53 on Ser15 does not occur in cells experiencing extended mitotic duration [50]. Overall this suggests that, despite the involvement of the same actors, the downstream effects imposed by p53 in order to control cell fate could diverge in response to DNA damage and extended mitotic duration, given the different mechanisms and interactors that lead to p53 stabilization and activation.

Maybe unsurprisingly, the accumulation of extra centrosomes, e.g., as experienced by cells after defective cytokinesis, utilizes yet again a different machinery to activate p53, limiting their expansion or survival [57]. Here, a multiprotein complex, dubbed the PIDDosome [58], is engaged to promote the activation of a cysteine-driven protease, caspase2, that can cleave MDM2, to neutralize this E3-ligase and to enable p53 stabilization. Of note, the N-terminal fragment of MDM2, devoid of its E3ligase domain, remains attached to $\mathrm{p} 53$ and phosphorylation events noted during the DDR, are not seen upon centrosome accumulation [57], again pointing towards qualitative and potentially quantitative differences in this type of p53 response (Figure 1).

\section{P53-induced cell cycle arrest and senescence}

As stated previously, the induction of cycle arrest appears intuitively helpful to prevent the outgrowth of a cell that has lost genome integrity, but this response, even in its most stringent form, i.e. senescence, appears to be overcome eventually during transformation or tumor therapy.

The potent cyclin dependent kinase inhibitor $(C D K N 1 A)$ p21 was the first transcriptional target of p53 to be identified as capable of regulating tumor growth upon p53 activation [12]. As other genes connected to the control of cell cycle, the CDKN1A locus contains two strong p53 response elements (at -2.3 and $-1.4 \mathrm{~kb}$ from the transcription start site [60], which allow a quick transcriptional upregulation of the CDKN1A gene upon p53 activation. The immediate result of p21 expression is the arrest of the cell cycle, which occurs via a p21-mediated inhibition of the cyclin/CDK complexes by physical interaction [21]. Inactivation of the cyclinE/ACDK2 and cyclinD-CDK4/6 complexes prevents CDK-mediated phosphorylation of $\mathrm{pRB}$, preventing the release of $\mathrm{E} 2 \mathrm{~F}$ transcription factors controlling the transition from G1 to the S phase [61,62] (Figure 2). Yet, by looking at the p53 core transcriptional program, additional genes besides $C D K N 1 A$ appear to be related to cell cycle control [63]. Of note, GADD45A is known to act in concert with p21 and SFN (also known as 14-3-3- $\sigma$, another p53 transcriptional target) to inhibit the cyclin B1/CDK1 complex necessary for the entry into mitosis [64,65]. In addition, p53 induces PLK2 and PLK3 that encode kinases belonging to the polo-like family, both of which play important roles in the maintenance of genome integrity in response to mitotic errors and DNA damage [66] (Figure 2). Moreover, a number of p53 targets that may indirectly impinge on cell 
cycle control have been reported, including DUSP14, CyclinG1, BTG2, NUPR1, ZMAT3, ZNF385A.

Besides transcriptional upregulation, high-throughput studies on cell lines exposed to p53 activating treatments repeatedly identified a plethora of genes whose expression was downregulated. Initially, it was considered that p53 could directly dampen the expression of these genes, therefore different models that could explain the repressive mechanism have been proposed. Nevertheless, experimental evidence from ChIP data failed to determine a direct connection between p53 binding to a DNA sequence on a given gene and a subsequent reduction on mRNA production [7].

\section{P53 and the DREAM complex}

The discovery of the DREAM complex was crucial to disentangle the mechanisms of p53-mediated target gene repression, which is now considered to be exclusively indirect through DREAM $[63,67,68]$ and strictly dependent on the presence of p21 [69]. The DREAM complex (dimerization partner (DM), RB-like, E2F and multi-vulval class B $(\mathrm{MuvB}))$ is a multiprotein machinery that, depending on the subunits interacting with the MuvB core, can bind with different regulatory elements on the promoter of target genes and, importantly, can act both as a transcriptional activator or repressor in a context-dependent manner [70]. A detailed review on the DREAM complex can be found in ref [71]. In physiological settings, cells are held in G1 (or G0) by the MuvB interacting with the pocket proteins p107 and p130, both of which are structurally and functionally related to $\mathrm{pRB}$ that bind in turn the repressor E2F4/5 (DREAM complex), resulting in downregulation of proproliferative E2F-responsive genes (Figure 2). Upon phosphorylation of p107/p130 by the cyclin/CDK complexes, the interaction with the MuvB core is terminated, allowing MuvB to bind B-MYB and/or FOXM1 forming the MMB (bMyb-MuvB) or the MMB-FOXM1 complexes. The latter complexes promote the transcription of target genes responsible for cell cycle progression through S, G2 and M phase [72,73]. Conversely, following p53 activation, p21-dependent inactivation of cyclin/CDKs complexes prevents the phosphorylation of p107/p130, arresting the switch from DREAM to MMB/MMB-FOXM1 complexes and repressing the transcription of target genes [74]. In this way, p53 indirectly downregulates the expression of several genes involved in DNA replication, G2 checkpoint and mitosis, expanding its cell cycle regulating potential beyond the simple induction of GADD45A, SNF and PLK2.

P53-induced senescence is considered a stable form of cycle arrest that involves alterations in cell metabolism, gene expression and chromatin composition and association with a specific senescence associated secretory phenotype (defined SASP) [75]. Induction of senescence is considered a multistep process, in which the initial cell cycle arrest is exerted by p21, becoming permanent via the subsequent activation of the CDK inhibitor p16/INK4a [75]. Similarly to transient cell cycle arrest, the DREAM complex contributes to p53-induced senescence. It was initially discovered that RNAi-mediated downregulation of the DREAM complex proteins LIN9, LIN54 and B-MYB results in premature senescence through activation of p53 in human fibroblasts [76]. Moreover, interfering with the phosphorylation of LIN52 (a protein composing the MuvB core) by downregulation of the kinase DYRK1A prevents the switch of the MuvB core from the activating to the cell cycle-repressive DREAM state, impinging the cells' ability to enter senescence [77]. 
Of note, knock-down of LIN9 in human fibroblasts in combination with p53 inactivation via SV40 results in high levels of aneuploidy [76]. A similar result was also observed in LIN9-deficient mouse embryonic fibroblasts (MEFs) that displayed a high degree of polyploidization, binucleation and other nuclear abnormalities already 24 hours after cell cycle re-entry, which ultimately lead to premature senescence [78]. These aberrations arise from defective cell division, like prolonged mitotic timing, failed cytokinesis, acquisition of extra centrosomes and formation of multipolar spindles in subsequent rounds of cell division. Not surprisingly, impairing the DREAM complex formation interferes with the cell division process, as the expression of many genes responsible for mitosis are controlled by the MuvB core in the repressor (DREAM) or activator (B-MYB/FOXM1) conformation. However, the high degree of aneuploidy reached by LIN9-deficient MEFs raises the question whether the activation of p53 and p21 (PIDDosome- and/or USP28-53BP1 dependent) is sufficient for preventing tumorigenesis and to which extent the downstream activation of p21 and DREAM is essential to prevent the outgrowth of multinucleated and/or aneuploid cells.

Recently, an interesting feedback loop was discovered that also connects the PIDDosome to the p53-p21 axis and cell cycle control. Indeed, besides being regulated by p53 (as PIDD1 is a transcriptional target of p53 itself [79]), Sladky et al discovered that during normal liver development or during regeneration, transcription factors of the E2F family control the expression of PIDD1 and CASP2. In this context, E2F1 promotes cell cycle progression as well as the upregulation of CASP2 and PIDD1, which limit polyploidization of liver cells. Conversely, E2F7 and E2F8 have an opposing role, reducing the expression of the PIDDosome components and allowing hepatocytes to reach their physiological polyploid status [80].

\section{P53-induced apoptosis}

Apoptosis is the best characterized form of p53-induced cell death (reviewed in Aubrey et al., 2018 [8]). Several transcriptional targets of p53 are tied to the intrinsic mitochondrial or extrinsic death receptor (DR)driven apoptotic pathways [63,81]. While differing in trigger and execution, both pathways depend on cysteine-aspartic proteases termed caspases to coordinate non-immunogenic apoptosis.

Certain cytotoxic insults such as DNA damage caused by UV- or ionizing radiation can activate the intrinsic apoptotic pathway through p53-driven expression of pro-apoptotic members of the BCL2 protein family [25,82-85]. Being comprised of pro-survival- and pro-apoptotic proteins, the BCL2 family members keep each other in check through direct protein-protein interactions mediated through their shared $\mathrm{BH}$ (BCL-2 homology) domains (reviewed in Czabotar et al., 2014 [86]). Prosurvival members, such as BCL2, BCLX and MCL1, bind and sequester pro-apoptotic "BH3-only" proteins including BID, PUMA and NOXA, impairing their ability to activate the apoptosis effector proteins BAX and BAK [87] (Figure 3). Amongst these apoptosis regulators, wellcharacterized p53 transcriptional targets include the $\mathrm{BH} 3$-only proteins PUMA/BBC3 [82], NOXA/PMAIP1 [85] and potentially also BID [88], as well as the apoptosis effector $B A X[89,90]$. These findings imply that p53 activity has direct consequences on apoptosis induction as its transcription of pro-apoptotic genes contributes to surpassing of the apoptotic threshold. 
Additionally, p53 may trigger apoptosis at mitochondria independently of transcription through direct protein-protein interactions. These include the direct engagement of mitochondria and binding of the pro-survival proteins BCL2 and BCLX [91,92]. Cytosolic p53 was further reported to directly activate BAX [93] and BAK upon mitochondrial translocation [94]. Mechanistically, p53's cytosolic proapoptotic function upon genotoxic stress has been suggested to be regulated through the transcription of its target gene PUMA, which in turn disrupts cytosolic BCLX/p53 complexes by competitive binding $[93,95]$. p53 binding of BCLX is meanwhile supported by crystal structure data [96] and has been successfully targeted in glioblastoma xenograft models to induce apoptosis [97]. Its interaction with the apoptosis effectors BAX and BAK, however, have been mainly addressed with recombinant protein studies or in overexpression settings. While these findings are intriguing, they remain controversial, as physiological settings where p53's direct protein-protein interactions become rate limiting for intrinsic apoptosis remain to be uncovered.

Once activated, BAX and BAK homo-oligomerize in the outer mitochondrial membrane, leading to the release of apoptotic mediators, including cytochrome $c$ and caspase-derepressing proteins. In the cytoplasm, cytochrome c interacts with APAF1 to promote the formation of the apoptosome, the activation platform of initiator caspase-9. Active caspase- 9 can then proteolytically activate executioner caspases (caspase$3,-6,-7)$, which orchestrate the breakdown of the cell. Intriguingly, p53 seems to tune apoptosis by regulating APAF1 expression [98,99]. Conversely, the p53-induced apoptosis inhibitor TRIAP1 has been reported to interfere with apoptosome formation [100,101] (Figure 3).

Extrinsic apoptosis is elicited by DRs that are transmembrane signaling molecules belonging to the tumor necrosis factor receptor (TNFR) superfamily (reviewed in Carneiro \& El-Deiry, 2020 [102]). P53 also intersects this pathway as it can regulate the expression of several DRs. This includes Fas (CD95/APO-1) [103] and the TRAIL receptors 1 (DR4/TNFRSF10A) [104] and 2 (DR5/KILLER/TNFRSF10B) [105] that respectively bind the apoptosis-initiating ligands FasL and TRAIL (TNFrelated apoptosis-inducing ligand). Ligand binding clusters these receptors, thereby forming signaling scaffolds via their specialized intracellular death domains (DD). These domains allow the recruitment of adaptor proteins such as FADD (Fas associated death domain), forming a death-inducing signaling complex (DISC), which serves as activation platform for the initiator caspases 8 and 10 [106-108]. In a cell type-specific manner these initiators can directly cleave and activate effector caspases (e.g. in lymphocytes) or drive apoptosis via the engagement of the mitochondrial apoptotic pathway (e.g. in hepatocytes). The latter is mediated by the $\mathrm{p} 53$ regulated $\mathrm{BH} 3$-only protein $\mathrm{BID}$, which is truncated and activated by caspase-8 [109,110] (Figure 3). On the contrary, through its transcriptional control of the DD-lacking decoy receptors TRAIL receptor 3 (TRID/TNFRSF10C) and 4 (TRUNDD/TNFRSF10D) p53 has also been reported to negatively regulate apoptosis [111,112].

Albeit the transcriptional activation of DR family proteins by p53 remains undisputed, its role in apoptosis in response to genotoxic stress in cancer vs. normal cells remains to be fully understood. It remains plausible that the expression of these TNFR family proteins by p53 contributes to sterile inflammatory signaling after cells experience DNA damage or undergo mitotic errors. 


\section{Non-apoptotic cell death forms regulated by p53}

Entosis is a form of non-apoptotic cell death in which one cell invades another, forming a cell-in-cell (CiC) structure. The presence of these structures has been noted in histological examination of tumor specimens already at the end of the $19^{\text {th }}$ century. It can involve different type of cells (both in terms of tissue derivation and oncogenic status) but not professional phagocytes $[113,114]$. Mechanistically, entosis requires actomyosin rearrangements that are driven by the GTPase RhoA and the effectors ROCK1 and ROCK2. Cytoskeletal rearrangements on the internalizing cell pushes it towards the future host and the invasion process requires adherent junction formation between the entotic and the host cell [115]. Once internalized, most entotic cells undergo cell death by a mechanism involving their lysosomal degradation. However, sometimes cells are either released from or remain alive within the host for extended periods of time [115]. This can interfere with the host cell division cycle and ultimately lead to aneuploidy [116]. Consistently, entosis can be either tumor suppressive or promoting, as the internalized cell can undergo cell death, but also interferes with normal cell division of the host, promoting aneuploidy. More recent reports identified how the p53 status of the invaded host can discriminate the pro- or antitumorigenic aspect of entosis. Mackay and colleagues [117] identified how a host cell bearing mutant p53 is more prone to form $\mathrm{CiC}$ structures and take advantage of the engulfed cell to create genetic diversity via aneuploidy while Durgan et al determined how adherent epithelial cells undergoing mitotic defects (such as prolonged metaphase arrest and/or changes in mitotic morphology) are more prone to be internalized by neighboring healthy cells. This phenomenon can potentially prevent the outgrowth of cells bearing genomic defects [118] (Figure 3). Along this line, Liang et al determined how entosis occurring following mitosis is controlled by p53, which is activated upon the DNA damage experienced by the cell undergoing prolonged mitotic arrest. In this context, p53 directly upregulates the expression of its target $R n d 3$, which directs the function of the RhoA-ROCK1 pathway to remodel the actomyosin filaments promoting the penetration of neighboring cells [119]. In this case, prolonged mitosis and the activation of the 53BP1-USP28 axis is not responsible for entosis, suggesting that p53 controls two independent mechanism aimed at preventing the growth of cells experiencing difficulties in metaphase: on the one had entosis and clearance by its neighbors and on the other hand the p21-mediated arrest in the next interphase [49-51]. If the 53BP1-USP28 axis can trigger p53-induced apoptosis in cells entering G1 phase remains to be investigated.

Ferroptosis is a non-apoptotic, caspase-independent form of cell death caused by extensive iron-dependent lipid peroxidation [120]. By altering the intracellular redox balance, p53 can both induce and block ferroptosis (reviewed in Kang et al [121]).

Physiological amounts of oxygenated phospholipids in the plasma membrane are reduced by the glutathione peroxidase GPX4 to prevent ferroptosis [122]. Through transcriptionally repressing SLC7A11, p53 reduces available intracellular antioxidant levels and promotes oxidative damage leading to ferroptosis induction [123]. SLC7A11 is part of the cystine/glutamate antiporter system $\mathrm{x}_{\mathrm{c}^{-}}$that is essential for sustaining reduced glutathione pools. In vivo studies found that mice harboring an acetylation-deficient, mutated form of p53 (3KR), which renders them resistant to apoptosis, cell cycle arrest and senescence, were still able to repress SLC7A11 and promote ferroptosis induction [123]. Moreover, 
mice expressing this $3 K R$ p53 mutant and lacking the DNA damage repair gene XRCC4 were found to be viable (while XRCC4 deficient mice are not) and protected from spontaneous tumorigenesis although showing high degrees of genomic instability [124]. As the authors find SLC7A11 downregulation and ferroptosis induction in these mice, they link regulation of ferroptosis to p53's function as a tumor suppressor (Figure 3). Another pro-ferroptotic gene controlled by p53 is the polyamine metabolizing enzyme SAT1 [125]. SAT1 overexpression sensitizes cells to ferroptosis, possibly through its downstream effects on the lipoxygenase ALOX15 [125]. When overexpressed in tumor cells in xenograft models, SAT1 limits tumor growth through ferroptosis induction, which was later shown to be additionally dependent on the lipoxygenase ALOX12 $[125,126]$. These findings provide further evidence on ferroptosis as a tumor suppressive effector arm of p53. Additional target genes involved in controlling this type of cell death include FDXR (ferredoxin reductase) [127] and GLS2 (glutaminase 2) [128].

Yet, as mentioned above, p53 serves antithetical functions in ferroptosis regulation, which may be explained by cell-type specific pathway alterations or PTMs such as acetylation [129]. For example, in wildtype colorectal cancer cells p53 was found to suppress erastininduced ferroptosis in a transcription-independent manner. This was suggested to rely on sequestration of dipeptidyl peptidase 4 (DPP4) in the nucleus, thereby limiting membrane peroxidation [130]. Another recent study found that the long-term stabilization of p53 and transcription of the cell cycle inhibitor p21 markedly delayed ferroptosis onset upon blocking of system $\mathrm{xc}^{-}$[131]. This delay required available, reduced glutathione pools, suggesting that cell cycle stage and metabolic activity timed by p53 affects a cell's susceptibility to ferroptosis [131]. Clearly, cell type and metabolic state will affect the outcome of p53-dependent changes in the signaling networks modulating ferroptosis susceptibility. Additional studies are needed to put these observations into context.

\section{Mitotic catastrophe, caspase-2 and the PIDDosome}

Mitosis is a tightly regulated process, as karyotype aberrations resulting from abnormal cell division can increase the susceptibility of daughter cells to malignant transformation (reviewed in Giam \& Rancati [27]). To maintain genome integrity, the outgrowth of aneuploid and chromosomally instable cells is attenuated by processes summarized as mitotic catastrophe (reviewed in Vitale et al [132]). Caspase-2 has been promoted as key executor in these pathways, which at least in part depend on p53 [133]. Caspase-2 has been implicated in a variety of biological functions including apoptosis induced by DNA-damage (reviewed in Brown-Suedel \& Bouchier-Hayes [134]). In this context, Tinel and Tschopp identified the PIDDosome as activation platform of caspase2 [58]. P53 activation has been seen as a crucial determinant of caspase-2induced cell death, primarily through the transcriptional regulation of PIDD1 [79]. While mouse genetics did not support a decisive role for the PIDDosome in DNA damage $[135,136]$, in vitro studies provided evidence that caspase-2 can cleave MDM2, the master regulator of p53 protein levels, upon DNA damage, placing p53 simultaneously up and downstream of caspase-2 [59].

How can this conundrum be reconciled? As it seems, both scenarios can be true. The PIDDosome/MDM2/p53 axis is central in the response to centrosome accumulation, e.g. after cytokinesis failure [57], placing caspase-2 upstream of p53. Alternatively, PIDDosome-activated caspase- 
2 has been proposed to act as a fail-safe mechanism by initiating a stable p53 response in cells that escape cell cycle arrest following DNA damage [137]. Here, caspase-2 may act as an important safeguard of genome integrity downstream of p53. Consistently, $\gamma$-irradiated caspase-2-null MEFs were found to fail undergoing apoptosis and continue cycling [138]. Furthermore, MEFs as well as MYC-induced B cell lymphomas from mice lacking caspase-2 show defective p53 signaling and increased aneuploidy $[139,140]$. Yet, the role of caspase-2 in clearing aneuploid cells as well as potential mechanisms involved needs to be clarified in future studies.

\section{Life-death decisions by p53 - flicking the switch}

What ultimately defines cell fate after p53 activation in diverse cell types? Over the years, different models have been proposed trying to explain how p53 imposes different phenotypes upon its activation, culminating in the re-entry into the cell cycle, the maintenance of an arrested phenotype (senescence) or the induction of cell death. As it seems, a consistent and universal predictor of the terminal phenotype has still to be determined, or simply does not exist. Intuitively, the type of damage experienced by the cell, its severity and duration in time can be crucial factors leading to either survival or death $[16,141]$. Indeed, an acute or sustained stressor will promote a higher magnitude of p53 activation or a sustained activation in time, which can result in the binding of weaker response elements, such as those situated on pro-apoptotic genes [9]. Nevertheless, this model does not hold universally true, e.g., cells belonging to different tissues show a different sensitivity towards the same p53-activating trigger $[142,143]$, hinting towards a more complex network regulating the choice between life and death.

The discovery of the pulsatile nature of p53 activity over time [144] opens a different scenario in the determination of the choice between life and death, as cells showing an oscillating activation of p53 are more prone to repair DNA damage and survive, whereas a sustained p53 activation (either cell type specific or treatment-dependent) is associated to senescence [145] and ferroptosis resistance [131].

The oscillatory behavior observed is due to the feedback loop between p53 and MDM2 [144]. If cells slip out of the arrest and re-enter the cell cycle before the DNA damage is completely repaired, p53 is reactivated with a sustained dynamics thanks to the action of the PIDDosome, which inactivates MDM2 upon completion of mitosis in the presence of unrepaired DNA damage and allows the establishment of a sustained p53 activation [137]. Conversely, apoptosis is induced only upon a quicker induction of the protein, compared to surviving cells and is triggered only in cells that reach a certain threshold of p53 accumulation $[146,147]$. Surprisingly though, activation dynamics do not influence the binding potential of the protein to its response elements [148], suggesting that phenotype decision rather occurs post-transcriptionally. This is in line with the findings of Andrysik and collaborators [63]: cell lines exposed to the same p53 activating stimulus, but showing a different outcome to the treatment (i.e. cell death or apoptosis) share a nearly identical transcriptome (comprising also apoptotic modulators in cell cycle-arresting cells). However, at the translatome level, the ensemble of mRNA that are actively translated changes dramatically between cell lines, where apoptosis mediators are bound to ribosomes and translated much before apoptosis onset in sensitive cells [63]. The translatome of apoptotic cells is strongly influenced by the intrinsic repertoire of RNA binding proteins (RBPs) that are present in those cells, shaping the 
phenotype at a post-transcriptional level [149]. Intriguingly, p53 itself can directly participate to post-transcriptional gene regulation by controlling the transcription of many RBPs and microRNAs [150,151].

\section{Conclusions}

p53 is at the center of a branching network of effector programs, including cell cycle arrest, senescence, and various forms of cell death. How exactly p53 makes the decision which program to initiate remains elusive but is at least in part stimulus- and cell type-dependent. As the complexity of the p53 responses observed and the network of players is constantly growing and far from being disentangled, research on the most studied tumor suppressor gene needs to continue to provide satisfactory context and cell type-dependent answers that will eventually help to harness p53 for cancer treatment.

Acknowledgments: Work in our laboratory is currently supported by the Austrian Science Fund, FWF, (P 29499), the Austrian Academy of Sciences, (OeAW), the Ludwig Boltzmann Society, (LBG), and the ERC-AdG "POLICE" (\#787171).

\section{References}

1. Báez, A. Genetic and Environmental Factors in Head and Neck Cancer Genesis. Journal of Environmental Science and Health, Part C 2008, 26, 174-200, doi:10.1080/10590500802129431.

2. Landi, S. Genetic Predisposition and Environmental Risk Factors to Pancreatic Cancer: A Review of the Literature. Mutation Research/Reviews in Mutation Research 2009, 681, 299-307, doi:10.1016/j.mrrev.2008.12.001.

3. Moore, E.E.; Wark, J.D.; Hopper, J.L.; Erbas, B.; Garland, S.M.; CeCaGeEn Study Group The Roles of Genetic and Environmental Factors on Risk of Cervical Cancer: A Review of Classical Twin Studies. Twin Res Hum Genet 2012, 15, 79-86, doi:10.1375/twin.15.1.79.

4. Nickels, S.; Truong, T.; Hein, R.; Stevens, K.; Buck, K.; Behrens, S.; Eilber, U.; Schmidt, M.; Häberle, L.; Vrieling, A.; et al. Evidence of Gene-Environment Interactions between Common Breast Cancer Susceptibility Loci and Established Environmental Risk Factors. PLoS Genet 2013, 9, e1003284, doi:10.1371/journal.pgen.1003284.

5. Rahman, M.S.; Suresh, S.; Waly, M.I. Risk Factors for Cancer: Genetic and Environment. In Bioactive Components, Diet and Medical Treatment in Cancer Prevention; Waly, M.I., Rahman, M.S., Eds.; Springer International Publishing: Cham, 2018; pp. 1-23 ISBN 978-3-319-75692-9.

6. Rudolph, A.; Chang-Claude, J.; Schmidt, M.K. Gene-Environment Interaction and Risk of Breast Cancer. $\mathrm{Br} J$ Cancer 2016, 114, 125-133, doi:10.1038/bjc.2015.439.

7. Sullivan, K.D.; Galbraith, M.D.; Andrysik, Z.; Espinosa, J.M. Mechanisms of Transcriptional Regulation by P53. Cell Death Differ 2018, 25, 133-143, doi:10.1038/cdd.2017.174.

8. Aubrey, B.J.; Kelly, G.L.; Janic, A.; Herold, M.J.; Strasser, A. How Does P53 Induce Apoptosis and How Does This Relate to P53-Mediated Tumour Suppression? Cell Death Differ 2018, 25, 104-113, doi:10.1038/cdd.2017.169.

9. Chen, J. The Cell-Cycle Arrest and Apoptotic Functions of P53 in Tumor Initiation and Progression. Cold Spring Harb Perspect Med 2016, 6, a026104, doi:10.1101/cshperspect.a026104.

10. Hofseth, L.J.; Hussain, S.P.; Harris, C.C. P53: 25 Years after Its Discovery. Trends in Pharmacological Sciences 2004, 25, 177-181, doi:10.1016/j.tips.2004.02.009.

11. Kastenhuber, E.R.; Lowe, S.W. Putting P53 in Context. Cell 2017, 170, 1062-1078, doi:10.1016/j.cell.2017.08.028.

12. El-Deiry, W.S.; Tokino, T.; Velculescu, V.E.; Levy, D.B.; Parsons, R.; Trent, J.M.; Lin, D.; Mercer, W.E.; Kinzler, K.W.; Vogelstein, B. WAF1, a Potential Mediator of P53 Tumor Suppression. Cell 1993, 75, 817-825, doi:10.1016/0092-8674(93)90500-P.

13. Amaral, J.D.; Xavier, J.M.; Steer, C.J.; Rodrigues, C.M. The Role of P53 in Apoptosis. Discovery Medicine 2010, 9, 145-152.

14. Bieging, K.T.; Mello, S.S.; Attardi, L.D. Unravelling Mechanisms of P53-Mediated Tumour Suppression. Nat Rev Cancer 2014, 14, 359-370, doi:10.1038/nrc3711.

15. Humpton, T.; Vousden, K.H. Taking up the Reins of Power: Metabolic Functions of P53. Journal of Molecular Cell Biology 2019, 11, 610-614, doi:10.1093/jmcb/mjz065.

16. Vousden, K.H.; Prives, C. Blinded by the Light: The Growing Complexity of P53. Cell 2009, 137, 413-431, doi:10.1016/j.cell.2009.04.037. 
17. Li, T.; Kon, N.; Jiang, L.; Tan, M.; Ludwig, T.; Zhao, Y.; Baer, R.; Gu, W. Tumor Suppression in the Absence of P53-Mediated Cell-Cycle Arrest, Apoptosis, and Senescence. Cell 2012, 149, 1269-1283, doi:10.1016/j.cell.2012.04.026.

18. Valente, L.J.; Gray, D.H.D.; Michalak, E.M.; Pinon-Hofbauer, J.; Egle, A.; Scott, C.L.; Janic, A.; Strasser, A. P53 Efficiently Suppresses Tumor Development in the Complete Absence of Its Cell-Cycle Inhibitory and Proapoptotic Effectors P21, Puma, and Noxa. Cell Reports 2013, 3, 1339-1345, doi:10.1016/j.celrep.2013.04.012.

19. Aylon, Y.; Oren, M. P53: Guardian of Ploidy. Molecular Oncology 2011, 5, 315-323, doi:10.1016/j.molonc.2011.07.007.

20. Gronroos, E.; López-García, C. Tolerance of Chromosomal Instability in Cancer: Mechanisms and Therapeutic Opportunities. Cancer Res 2018, 78, 6529-6535, doi:10.1158/0008-5472.CAN-18-1958.

21. Abbas, T.; Dutta, A. P21 in Cancer: Intricate Networks and Multiple Activities. Nat Rev Cancer 2009, 9, 400414, doi:10.1038/nrc2657.

22. Dansen, T.B.; Whitfield, J.; Rostker, F.; Brown-Swigart, L.; Evan, G.I. Specific Requirement for Bax, Not Bak, in Myc-Induced Apoptosis and Tumor Suppression in Vivo*. Journal of Biological Chemistry 2006, 281, 1089010895, doi:10.1074/jbc.M513655200.

23. Eischen, C.M.; Roussel, M.F.; Korsmeyer, S.J.; Cleveland, J.L. Bax Loss Impairs Myc-Induced Apoptosis and Circumvents the Selection of P53 Mutations during Myc-Mediated Lymphomagenesis. Molecular and Cellular Biology 2001, 21, 7653-7662, doi:10.1128/MCB.21.22.7653-7662.2001.

24. Hemann, M.T.; Zilfou, J.T.; Zhao, Z.; Burgess, D.J.; Hannon, G.J.; Lowe, S.W. Suppression of Tumorigenesis by the P53 Target PUMA. Proc Natl Acad Sci U S A 2004, 101, 9333-9338, doi:10.1073/pnas.0403286101.

25. Michalak, E.M.; Jansen, E.S.; Happo, L.; Cragg, M.S.; Tai, L.; Smyth, G.K.; Strasser, A.; Adams, J.M.; Scott, C.L. Puma and to a Lesser Extent Noxa Are Suppressors of Myc-Induced Lymphomagenesis. Cell Death Differ 2009, 16, 684-696, doi:10.1038/cdd.2008.195.

26. Valente, L.J.; Grabow, S.; Vandenberg, C.J.; Strasser, A.; Janic, A. Combined Loss of PUMA and P21 Accelerates C-MYC-Driven Lymphoma Development Considerably Less than Loss of One Allele of P53. Oncogene 2016, 35, 3866-3871, doi:10.1038/onc.2015.457.

27. Giam, M.; Rancati, G. Aneuploidy and Chromosomal Instability in Cancer: A Jackpot to Chaos. Cell Div 2015, 10, 3, doi:10.1186/s13008-015-0009-7.

28. Sanchez, Y.; Wong, C.; Thoma, R.S.; Richman, R.; Wu, Z.; Piwnica-Worms, H.; Elledge, S.J. Conservation of the Chk1 Checkpoint Pathway in Mammals: Linkage of DNA Damage to Cdk Regulation Through Cdc25. Science 1997, 277, 1497-1501, doi:10.1126/science.277.5331.1497.

29. Faesen, A.C.; Thanasoula, M.; Maffini, S.; Breit, C.; Müller, F.; van Gerwen, S.; Bange, T.; Musacchio, A. Basis of Catalytic Assembly of the Mitotic Checkpoint Complex. Nature 2017, 542, 498-502, doi:10.1038/nature21384.

30. Maresca, T.J.; Salmon, E.D. Welcome to a New Kind of Tension: Translating Kinetochore Mechanics into a Wait-Anaphase Signal. Journal of Cell Science 2010, 123, 825-835, doi:10.1242/jcs.064790.

31. Holland, A.J.; Cleveland, D.W. Boveri Revisited: Chromosomal Instability, Aneuploidy and Tumorigenesis. Nat Rev Mol Cell Biol 2009, 10, 478-487, doi:10.1038/nrm2718.

32. Levine, M.S.; Holland, A.J. The Impact of Mitotic Errors on Cell Proliferation and Tumorigenesis. Genes Dev. 2018, 32, 620-638, doi:10.1101/gad.314351.118.

33. Nigg, E.A.; Holland, A.J. Once and Only Once: Mechanisms of Centriole Duplication and Their Deregulation in Disease. Nat Rev Mol Cell Biol 2018, 19, 297-312, doi:10.1038/nrm.2017.127.

34. Thompson, S.L.; Bakhoum, S.F.; Compton, D.A. Mechanisms of Chromosomal Instability. Current Biology 2010, 20, R285-R295, doi:10.1016/j.cub.2010.01.034.

35. Williams, B.R.; Prabhu, V.R.; Hunter, K.E.; Glazier, C.M.; Whittaker, C.A.; Housman, D.E.; Amon, A. Aneuploidy Affects Proliferation and Spontaneous Immortalization in Mammalian Cells. Science 2008, 322, 703-709, doi:10.1126/science.1160058.

36. Ben-David, U.; Amon, A. Context Is Everything: Aneuploidy in Cancer. Nat Rev Genet 2020, 21, 44-62, doi:10.1038/s41576-019-0171-x.

37. Sansregret, L.; Vanhaesebroeck, B.; Swanton, C. Determinants and Clinical Implications of Chromosomal Instability in Cancer. Nat Rev Clin Oncol 2018, 15, 139-150, doi:10.1038/nrclinonc.2017.198.

38. Chunduri, N.K.; Storchová, Z. The Diverse Consequences of Aneuploidy. Nat Cell Biol 2019, 21, 54-62, doi:10.1038/s41556-018-0243-8.

39. Ohashi, A.; Ohori, M.; Iwai, K.; Nakayama, Y.; Nambu, T.; Morishita, D.; Kawamoto, T.; Miyamoto, M.; Hirayama, T.; Okaniwa, M.; et al. Aneuploidy Generates Proteotoxic Stress and DNA Damage Concurrently with P53-Mediated Post-Mitotic Apoptosis in SAC-Impaired Cells. Nat Commun 2015, 6, 7668, doi:10.1038/ncomms8668.

40. Pfau, S.J.; Silberman, R.E.; Knouse, K.A.; Amon, A. Aneuploidy Impairs Hematopoietic Stem Cell Fitness and Is Selected against in Regenerating Tissues in Vivo. Genes Dev. 2016, doi:10.1101/gad.278820.116.

41. Green, R.A.; Paluch, E.; Oegema, K. Cytokinesis in Animal Cells. Annu. Rev. Cell Dev. Biol. 2012, 28, 29-58, doi:10.1146/annurev-cellbio-101011-155718. 
42. Lens, S.M.A.; Medema, R.H. Cytokinesis Defects and Cancer. Nat Rev Cancer 2019, 19, 32-45, doi:10.1038/s41568-018-0084-6.

43. Zack, T.I.; Schumacher, S.E.; Carter, S.L.; Cherniack, A.D.; Saksena, G.; Tabak, B.; Lawrence, M.S.; Zhang, C.Z.; Wala, J.; Mermel, C.H.; et al. Pan-Cancer Patterns of Somatic Copy Number Alteration. Nat Genet 2013, 45, 1134-1140, doi:10.1038/ng.2760.

44. Ganem, N.J.; Godinho, S.A.; Pellman, D. A Mechanism Linking Extra Centrosomes to Chromosomal Instability. Nature 2009, 460, 278-282, doi:10.1038/nature08136.

45. Sanchez, A.D.; Feldman, J.L. Microtubule-Organizing Centers: From the Centrosome to Non-Centrosomal Sites. Current Opinion in Cell Biology 2017, 44, 93-101, doi:10.1016/j.ceb.2016.09.003.

46. Chan, J.Y. A Clinical Overview of Centrosome Amplification in Human Cancers. Int. J. Biol. Sci. 2011, 7, 11221144, doi:10.7150/ijbs.7.1122.

47. Godinho, S.A.; Picone, R.; Burute, M.; Dagher, R.; Su, Y.; Leung, C.T.; Polyak, K.; Brugge, J.S.; Théry, M.; Pellman, D. Oncogene-like Induction of Cellular Invasion from Centrosome Amplification. Nature 2014, 510, 167-171, doi:10.1038/nature13277.

48. Thompson, S.L.; Compton, D.A. Proliferation of Aneuploid Human Cells Is Limited by a P53-Dependent Mechanism. Journal of Cell Biology 2010, 188, 369-381, doi:10.1083/jcb.200905057.

49. Fong, C.S.; Mazo, G.; Das, T.; Goodman, J.; Kim, M.; O’Rourke, B.P.; Izquierdo, D.; Tsou, M.-F.B. 53BP1 and USP28 Mediate P53-Dependent Cell Cycle Arrest in Response to Centrosome Loss and Prolonged Mitosis. eLife 2016, 5, e16270, doi:10.7554/eLife.16270.

50. Lambrus, B.G.; Daggubati, V.; Uetake, Y.; Scott, P.M.; Clutario, K.M.; Sluder, G.; Holland, A.J. A USP2853BP1-P53-P21 Signaling Axis Arrests Growth after Centrosome Loss or Prolonged Mitosis. Journal of Cell Biology 2016, 214, 143-153, doi:10.1083/jcb.201604054.

51. Meitinger, F.; Anzola, J.V.; Kaulich, M.; Richardson, A.; Stender, J.D.; Benner, C.; Glass, C.K.; Dowdy, S.F.; Desai, A.; Shiau, A.K.; et al. 53BP1 and USP28 Mediate P53 Activation and G1 Arrest after Centrosome Loss or Extended Mitotic Duration. Journal of Cell Biology 2016, 214, 155-166, doi:10.1083/jcb.201604081.

52. Panier, S.; Boulton, S.J. Double-Strand Break Repair: 53BP1 Comes into Focus. Nat Rev Mol Cell Biol 2014, 15, 7-18, doi:10.1038/nrm3719.

53. Lakin, N.D.; Jackson, S.P. Regulation of P53 in Response to DNA Damage. Oncogene 1999, 18, 7644-7655, doi:10.1038/sj.onc.1203015.

54. Olsson, A.; Manzl, C.; Strasser, A.; Villunger, A. How Important Are Post-Translational Modifications in P53 for Selectivity in Target-Gene Transcription and Tumour Suppression? Cell Death Differ 2007, 14, 1561-1575, doi:10.1038/sj.cdd.4402196.

55. Zimmermann, M. 53BP1: Pro Choice in DNA Repair. 2014, 24, 10.

56. Cuella-Martin, R.; Oliveira, C.; Lockstone, H.E.; Snellenberg, S.; Grolmusova, N.; Chapman, J.R. 53BP1 Integrates DNA Repair and P53-Dependent Cell Fate Decisions via Distinct Mechanisms. Molecular Cell 2016, 64, 51-64, doi:10.1016/j.molcel.2016.08.002.

57. Fava, L.L.; Schuler, F.; Sladky, V.; Haschka, M.D.; Soratroi, C.; Eiterer, L.; Demetz, E.; Weiss, G.; Geley, S.; Nigg, E.A.; et al. The PIDDosome Activates P53 in Response to Supernumerary Centrosomes. Genes Dev. 2017, 31, 34-45, doi:10.1101/gad.289728.116.

58. Tinel, A.; Tschopp, J. The PIDDosome, a Protein Complex Implicated in Activation of Caspase-2 in Response to Genotoxic Stress. Science 2004, 304, 843-846, doi:10.1126/science.1095432.

59. Oliver, T.G.; Meylan, E.; Chang, G.P.; Xue, W.; Burke, J.R.; Humpton, T.J.; Hubbard, D.; Bhutkar, A.; Jacks, T. Caspase-2-Mediated Cleavage of Mdm2 Creates a P53-Induced Positive Feedback Loop. Molecular Cell 2011, 43, 57-71, doi:10.1016/j.molcel.2011.06.012.

60. Resnick-Silverman, L.; Clair, S.S.; Maurer, M.; Zhao, K.; Manfredi, J.J. Identification of a Novel Class of Genomic DNA-Binding Sites Suggests a Mechanism for Selectivity in Target Gene Activation by the Tumor Suppressor Protein P53. Genes Dev. 1998, 12, 2102-2107, doi:10.1101/gad.12.14.2102.

61. Al Bitar, S.; Gali-Muhtasib, H. The Role of the Cyclin Dependent Kinase Inhibitor P21cip1/Waf1 in Targeting Cancer: Molecular Mechanisms and Novel Therapeutics. Cancers (Basel) 2019, 11, 1475, doi:10.3390/cancers11101475.

62. Giacinti, C.; Giordano, A. RB and Cell Cycle Progression. Oncogene 2006, 25, 5220-5227, doi:10.1038/sj.onc.1209615.

63. Andrysik, Z.; Galbraith, M.D.; Guarnieri, A.L.; Zaccara, S.; Sullivan, K.D.; Pandey, A.; MacBeth, M.; Inga, A.; Espinosa, J.M. Identification of a Core TP53 Transcriptional Program with Highly Distributed Tumor Suppressive Activity. Genome Res. 2017, 27, 1645-1657, doi:10.1101/gr.220533.117.

64. Taylor, W.R.; Stark, G.R. Regulation of the G2/M Transition by P53. Oncogene 2001, 20, 1803-1815, doi:10.1038/sj.onc.1204252.

65. Zhan, Q. Gadd45a, a P53- and BRCA1-Regulated Stress Protein, in Cellular Response to DNA Damage. Mutation Research/Fundamental and Molecular Mechanisms of Mutagenesis 2005, 569, 133-143, doi:10.1016/j.mrfmmm.2004.06.055. 
66. Eckerdt, F.; Yuan, J.; Strebhardt, K. Polo-like Kinases and Oncogenesis. Oncogene 2005, 24, 267-276, doi:10.1038/sj.onc.1208273.

67. Fischer, M.; Steiner, L.; Engeland, K. The Transcription Factor P53: Not a Repressor, Solely an Activator. Cell Cycle 2014, 13, 3037-3058, doi:10.4161/15384101.2014.949083.

68. Fischer, M.; Quaas, M.; Steiner, L.; Engeland, K. The P53-P21-DREAM-CDE/CHR Pathway Regulates G2/M Cell Cycle Genes. Nucleic Acids Research 2016, 44, 164-174, doi:10.1093/nar/gkv927.

69. Fischer, M.; Grossmann, P.; Padi, M.; DeCaprio, J.A. Integration of TP53, DREAM, MMB-FOXM1 and RB-E2F Target Gene Analyses Identifies Cell Cycle Gene Regulatory Networks. Nucleic Acids Research 2016, 44, 60706086, doi:10.1093/nar/gkw523.

70. Sadasivam, S.; DeCaprio, J.A. The DREAM Complex: Master Coordinator of Cell Cycle-Dependent Gene Expression. Nat Rev Cancer 2013, 13, 585-595, doi:10.1038/nrc3556.

71. Engeland, K. Cell Cycle Arrest through Indirect Transcriptional Repression by P53: I Have a DREAM. Cell Death Differ 2018, 25, 114-132, doi:10.1038/cdd.2017.172.

72. Graña, X.; Garriga, J.; Mayol, X. Role of the Retinoblastoma Protein Family, PRB, P107 and P130 in the Negative Control of Cell Growth. Oncogene 1998, 17, 3365-3383, doi:10.1038/sj.onc.1202575.

73. Stengel, K.R.; Thangavel, C.; Solomon, D.A.; Angus, S.P.; Zheng, Y.; Knudsen, E.S. Retinoblastoma/P107/P130 Pocket Proteins: PROTEIN DYNAMICS AND INTERACTIONS WITH TARGET GENE PROMOTERS. Journal of Biological Chemistry 2009, 284, 19265-19271, doi:10.1074/jbc.M808740200.

74. Quaas, M.; Müller, G.A.; Engeland, K. P53 Can Repress Transcription of Cell Cycle Genes through a P21WAF1/CIP1-Dependent Switch from MMB to DREAM Protein Complex Binding at CHR Promoter Elements. Cell Cycle 2012, 11, 4661-4672, doi:10.4161/cc.22917.

75. Kumari, R.; Jat, P. Mechanisms of Cellular Senescence: Cell Cycle Arrest and Senescence Associated Secretory Phenotype. Frontiers in Cell and Developmental Biology 2021, 9, 485, doi:10.3389/fcell.2021.645593.

76. Hauser, S.; Ulrich, T.; Wurster, S.; Schmitt, K.; Reichert, N.; Gaubatz, S. Loss of LIN9, a Member of the DREAM Complex, Cooperates with SV40 Large T Antigen to Induce Genomic Instability and Anchorage-Independent Growth. Oncogene 2012, 31, 1859-1868, doi:10.1038/onc.2011.364.

77. Litovchick, L.; Florens, L.A.; Swanson, S.K.; Washburn, M.P.; DeCaprio, J.A. DYRK1A Protein Kinase Promotes Quiescence and Senescence through DREAM Complex Assembly. Genes Dev. 2011, 25, 801-813, doi:10.1101/gad.2034211.

78. Reichert, N.; Wurster, S.; Ulrich, T.; Schmitt, K.; Hauser, S.; Probst, L.; Götz, R.; Ceteci, F.; Moll, R.; Rapp, U.; et al. Lin9, a Subunit of the Mammalian DREAM Complex, Is Essential for Embryonic Development, for Survival of Adult Mice, and for Tumor Suppression. Molecular and Cellular Biology 2010, 30, 2896-2908, doi:10.1128/MCB.00028-10.

79. Lin, Y.; Ma, W.; Benchimol, S. Pidd, a New Death-Domain-Containing Protein, Is Induced by P53 and Promotes Apoptosis. Nat Genet 2000, 26, 122-127, doi:10.1038/79102.

80. Sladky, V.C.; Knapp, K.; Soratroi, C.; Heppke, J.; Eichin, F.; Rocamora-Reverte, L.; Szabo, T.G.; Bongiovanni, L.; Westendorp, B.; Moreno, E.; et al. E2F-Family Members Engage the PIDDosome to Limit Hepatocyte Ploidy in Liver Development and Regeneration. Developmental Cell 2020, 52, 335-349.e7, doi:10.1016/j.devcel.2019.12.016.

81. Fischer, M. Census and Evaluation of P53 Target Genes. Oncogene 2017, 36, 3943-3956, doi:10.1038/onc.2016.502.

82. Nakano, K.; Vousden, K.H. PUMA, a Novel Proapoptotic Gene, Is Induced by P53. Molecular Cell 2001, 7, 683694, doi:10.1016/S1097-2765(01)00214-3.

83. Villunger, A.; Michalak, E.M.; Coultas, L.; Müllauer, F.; Böck, G.; Ausserlechner, M.J.; Adams, J.M.; Strasser, A. P53- and Drug-Induced Apoptotic Responses Mediated by BH3-Only Proteins Puma and Noxa. Science 2003, 302, 1036-1038, doi:10.1126/science.1090072.

84. Naik, E.; Michalak, E.M.; Villunger, A.; Adams, J.M.; Strasser, A. Ultraviolet Radiation Triggers Apoptosis of Fibroblasts and Skin Keratinocytes Mainly via the BH3-Only Protein Noxa. Journal of Cell Biology 2007, 176, 415-424, doi:10.1083/jcb.200608070.

85. Oda, E.; Ohki, R.; Murasawa, H.; Nemoto, J.; Shibue, T.; Yamashita, T.; Tokino, T.; Taniguchi, T.; Tanaka, $†$ Nobuyuki Noxa, a BH3-Only Member of the Bcl-2 Family and Candidate Mediator of P53-Induced Apoptosis. Science 2000, 288, 1053-1058, doi:10.1126/science.288.5468.1053.

86. Czabotar, P.E.; Lessene, G.; Strasser, A.; Adams, J.M. Control of Apoptosis by the BCL-2 Protein Family: Implications for Physiology and Therapy. Nat Rev Mol Cell Biol 2014, 15, 49-63, doi:10.1038/nrm3722.

87. Letai, A.; Bassik, M.C.; Walensky, L.D.; Sorcinelli, M.D.; Weiler, S.; Korsmeyer, S.J. Distinct BH3 Domains Either Sensitize or Activate Mitochondrial Apoptosis, Serving as Prototype Cancer Therapeutics. Cancer Cell 2002, 2, 183-192, doi:10.1016/S1535-6108(02)00127-7.

88. Sax, J.K.; Fei, P.; Murphy, M.E.; Bernhard, E.; Korsmeyer, S.J.; El-Deiry, W.S. BID Regulation by P53 Contributes to Chemosensitivity. Nat Cell Biol 2002, 4, 842-849, doi:10.1038/ncb866. 
89. Selvakumaran, M.; Lin, H.K.; Miyashita, T.; Wang, H.G.; Krajewski, S.; Reed, J.C.; Hoffman, B.; Liebermann, D. Immediate Early Up-Regulation of Bax Expression by P53 but Not TGF Beta 1: A Paradigm for Distinct Apoptotic Pathways. Oncogene 1994, 9, 1791-1798.

90. Toshiyuki, M.; Reed, J.C. Tumor Suppressor P53 Is a Direct Transcriptional Activator of the Human Bax Gene. Cell 1995, 80, 293-299, doi:10.1016/0092-8674(95)90412-3.

91. Marchenko, N.D.; Zaika, A.; Moll, U.M. Death Signal-Induced Localization of P53 Protein to Mitochondria: A POTENTIAL ROLE IN APOPTOTIC SIGNALING*. Journal of Biological Chemistry 2000, 275, 16202-16212, doi:10.1074/jbc.275.21.16202.

92. Mihara, M.; Erster, S.; Zaika, A.; Petrenko, O.; Chittenden, T.; Pancoska, P.; Moll, U.M. P53 Has a Direct Apoptogenic Role at the Mitochondria. Molecular Cell 2003, 11, 577-590, doi:10.1016/S1097-2765(03)00050-9.

93. Chipuk, J.E.; Kuwana, T.; Bouchier-Hayes, L.; Droin, N.M.; Newmeyer, D.D.; Schuler, M.; Green, D.R. Direct Activation of Bax by P53 Mediates Mitochondrial Membrane Permeabilization and Apoptosis. Science 2004, 303, 1010-1014, doi:10.1126/science.1092734.

94. Leu, J.I.-J.; Dumont, P.; Hafey, M.; Murphy, M.E.; George, D.L. Mitochondrial P53 Activates Bak and Causes Disruption of a Bak-Mcl1 Complex. Nat Cell Biol 2004, 6, 443-450, doi:10.1038/ncb1123.

95. Follis, A.V.; Chipuk, J.E.; Fisher, J.C.; Yun, M.-K.; Grace, C.R.; Nourse, A.; Baran, K.; Ou, L.; Min, L.; White, S.W.; et al. PUMA Binding Induces Partial Unfolding within BCL-XL to Disrupt P53 Binding and Promote Apoptosis. Nat Chem Biol 2013, 9, 163-168, doi:10.1038/nchembio.1166.

96. Wei, H.; Qu, L.; Dai, S.; Li, Y.; Wang, H.; Feng, Y.; Chen, X.; Jiang, L.; Guo, M.; Li, J.; et al. Structural Insight into the Molecular Mechanism of P53-Mediated Mitochondrial Apoptosis. Nat Commun 2021, 12, 2280, doi:10.1038/s41467-021-22655-6.

97. Mai, W.X.; Gosa, L.; Daniels, V.W.; Ta, L.; Tsang, J.E.; Higgins, B.; Gilmore, W.B.; Bayley, N.A.; Harati, M.D.; Lee, J.T.; et al. Cytoplasmic P53 Couples Oncogene-Driven Glucose Metabolism to Apoptosis and Is a Therapeutic Target in Glioblastoma. Nat Med 2017, 23, 1342-1351, doi:10.1038/nm.4418.

98. Kannan, K.; Kaminski, N.; Rechavi, G.; Jakob-Hirsch, J.; Amariglio, N.; Givol, D. DNA Microarray Analysis of Genes Involved in P53 Mediated Apoptosis: Activation of Apaf-1. Oncogene 2001, 20, 3449-3455, doi:10.1038/sj.onc.1204446.

99. Robles, A.I.; Bemmels, N.A.; Foraker, A.B.; Harris, C.C. APAF-1 Is a Transcriptional Target of P53 in DNA Damage-Induced Apoptosis. Cancer Res 2001, 61, 6660-6664.

100. Potting, C.; Tatsuta, T.; König, T.; Haag, M.; Wai, T.; Aaltonen, M.J.; Langer, T. TRIAP1/PRELI Complexes Prevent Apoptosis by Mediating Intramitochondrial Transport of Phosphatidic Acid. Cell Metabolism 2013, 18, 287-295, doi:10.1016/j.cmet.2013.07.008.

101. Park, W.-R.; Nakamura, Y. P53CSV, a Novel P53-Inducible Gene Involved in the P53-Dependent Cell-Survival Pathway. Cancer Res 2005, 65, 1197-1206, doi:10.1158/0008-5472.CAN-04-3339.

102. Carneiro, B.A.; El-Deiry, W.S. Targeting Apoptosis in Cancer Therapy. Nat Rev Clin Oncol 2020, 17, 395-417, doi:10.1038/s41571-020-0341-y.

103. Müller, M.; Wilder, S.; Bannasch, D.; Israeli, D.; Lehlbach, K.; Li-Weber, M.; Friedman, S.L.; Galle, P.R.; Stremmel, W.; Oren, M.; et al. P53 Activates the CD95 (APO-1/Fas) Gene in Response to DNA Damage by Anticancer Drugs. Journal of Experimental Medicine 1998, 188, 2033-2045, doi:10.1084/jem.188.11.2033.

104. Liu, X.; Yue, P.; Khuri, F.R.; Sun, S.-Y. P53 Upregulates Death Receptor 4 Expression through an Intronic P53 Binding Site. Cancer Res 2004, 64, 5078-5083, doi:10.1158/0008-5472.CAN-04-1195.

105. Wu, G.S.; Burns, T.F.; McDonald, E.R.; Jiang, W.; Meng, R.; Krantz, I.D.; Kao, G.; Gan, D.-D.; Zhou, J.-Y.; Muschel, R.; et al. KILLER/DR5 Is a DNA Damage-Inducible P53-Regulated Death Receptor Gene. Nat Genet 1997, 17, 141-143, doi:10.1038/ng1097-141.

106. Sprick, M.R.; Weigand, M.A.; Rieser, E.; Rauch, C.T.; Juo, P.; Blenis, J.; Krammer, P.H.; Walczak, H. FADD/MORT1 and Caspase-8 Are Recruited to TRAIL Receptors 1 and 2 and Are Essential for Apoptosis Mediated by TRAIL Receptor 2. Immunity 2000, 12, 599-609, doi:10.1016/S1074-7613(00)80211-3.

107. Kischkel, F.C.; Lawrence, D.A.; Chuntharapai, A.; Schow, P.; Kim, K.J.; Ashkenazi, A. Apo2L/TRAILDependent Recruitment of Endogenous FADD and Caspase-8 to Death Receptors 4 and 5. Immunity 2000, 12, 611-620, doi:10.1016/S1074-7613(00)80212-5.

108. Bodmer, J.-L.; Holler, N.; Reynard, S.; Vinciguerra, P.; Schneider, P.; Juo, P.; Blenis, J.; Tschopp, J. TRAIL Receptor-2 Signals Apoptosis through FADD and Caspase-8. Nat Cell Biol 2000, 2, 241-243, doi: $10.1038 / 35008667$.

109. Li, H.; Zhu, H.; Xu, C.; Yuan, J. Cleavage of BID by Caspase 8 Mediates the Mitochondrial Damage in the Fas Pathway of Apoptosis. Cell 1998, 94, 491-501, doi:10.1016/S0092-8674(00)81590-1.

110. Luo, X.; Budihardjo, I.; Zou, H.; Slaughter, C.; Wang, X. Bid, a Bcl2 Interacting Protein, Mediates Cytochrome c Release from Mitochondria in Response to Activation of Cell Surface Death Receptors. Cell 1998, 94, 481490, doi:10.1016/S0092-8674(00)81589-5.

111. Liu, X.; Yue, P.; Khuri, F.R.; Sun, S.-Y. Decoy Receptor 2 (DcR2) Is a P53 Target Gene and Regulates Chemosensitivity. Cancer Res 2005, 65, 9169-9175, doi:10.1158/0008-5472.CAN-05-0939. 
112. Sheikh, M.S.; Huang, Y.; Fernandez-Salas, E.A.; El-Deiry, W.S.; Friess, H.; Amundson, S.; Yin, J.; Meltzer, S.J.; Holbrook, N.J.; Fornace, A.J. The Antiapoptotic Decoy Receptor TRID/TRAIL-R3 Is a P53-Regulated DNA Damage-Inducible Gene That Is Overexpressed in Primary Tumors of the Gastrointestinal Tract. Oncogene 1999, 18, 4153-4159, doi:10.1038/sj.onc.1202763.

113. Fais, S.; Overholtzer, M. Cell-in-Cell Phenomena in Cancer. Nat Rev Cancer 2018, 18, 758-766, doi:10.1038/s41568-018-0073-9.

114. Overholtzer, M.; Brugge, J.S. The Cell Biology of Cell-in-Cell Structures. Nat Rev Mol Cell Biol 2008, 9, 796-809, doi:10.1038/nrm2504.

115. Overholtzer, M.; Mailleux, A.A.; Mouneimne, G.; Normand, G.; Schnitt, S.J.; King, R.W.; Cibas, E.S.; Brugge, J.S. A Nonapoptotic Cell Death Process, Entosis, That Occurs by Cell-in-Cell Invasion. Cell 2007, 131, 966-979, doi:10.1016/j.cell.2007.10.040.

116. Krajcovic, M.; Johnson, N.B.; Sun, Q.; Normand, G.; Hoover, N.; Yao, E.; Richardson, A.L.; King, R.W.; Cibas, E.S.; Schnitt, S.J.; et al. A Non-Genetic Route to Aneuploidy in Human Cancers. Nat Cell Biol 2011, 13, 324-330, doi:10.1038/ncb2174.

117. Mackay, H.L.; Moore, D.; Hall, C.; Birkbak, N.J.; Jamal-Hanjani, M.; Karim, S.A.; Phatak, V.M.; Piñon, L.; Morton, J.P.; Swanton, C.; et al. Genomic Instability in Mutant P53 Cancer Cells upon Entotic Engulfment. Nat Commun 2018, 9, 3070, doi:10.1038/s41467-018-05368-1.

118. Durgan, J.; Tseng, Y.-Y.; Hamann, J.C.; Domart, M.-C.; Collinson, L.; Hall, A.; Overholtzer, M.; Florey, O. Mitosis Can Drive Cell Cannibalism through Entosis. eLife 2017, 6, e27134, doi:10.7554/eLife.27134.

119. Liang, J.; Niu, Z.; Zhang, B.; Yu, X.; Zheng, Y.; Wang, C.; Ren, H.; Wang, M.; Ruan, B.; Qin, H.; et al. P53Dependent Elimination of Aneuploid Mitotic Offspring by Entosis. Cell Death Differ 2021, 28, 799-813, doi:10.1038/s41418-020-00645-3.

120. Dixon, S.J.; Lemberg, K.M.; Lamprecht, M.R.; Skouta, R.; Zaitsev, E.M.; Gleason, C.E.; Patel, D.N.; Bauer, A.J.; Cantley, A.M.; Yang, W.S.; et al. Ferroptosis: An Iron-Dependent Form of Nonapoptotic Cell Death. Cell 2012, 149, 1060-1072, doi:10.1016/j.cell.2012.03.042.

121. Kang, R.; Kroemer, G.; Tang, D. The Tumor Suppressor Protein P53 and the Ferroptosis Network. Free Radical Biology and Medicine 2019, 133, 162-168, doi:10.1016/j.freeradbiomed.2018.05.074.

122. Yang, W.S.; SriRamaratnam, R.; Welsch, M.E.; Shimada, K.; Skouta, R.; Viswanathan, V.S.; Cheah, J.H.; Clemons, P.A.; Shamji, A.F.; Clish, C.B.; et al. Regulation of Ferroptotic Cancer Cell Death by GPX4. Cell 2014, 156, 317-331, doi:10.1016/j.cell.2013.12.010.

123. Jiang, L.; Kon, N.; Li, T.; Wang, S.-J.; Su, T.; Hibshoosh, H.; Baer, R.; Gu, W. Ferroptosis as a P53-Mediated Activity during Tumour Suppression. Nature 2015, 520, 57-62, doi:10.1038/nature14344.

124. Li, T.; Liu, X.; Jiang, L.; Manfredi, J.; Zha, S.; Gu, W. Loss of P53-Mediated Cell-Cycle Arrest, Senescence and Apoptosis Promotes Genomic Instability and Premature Aging. Oncotarget 2016, 7, 11838-11849, doi:10.18632/oncotarget.7864.

125. Ou, Y.; Wang, S.-J.; Li, D.; Chu, B.; Gu, W. Activation of SAT1 Engages Polyamine Metabolism with P53Mediated Ferroptotic Responses. PNAS 2016, 113, E6806-E6812, doi:10.1073/pnas.1607152113.

126. Chu, B.; Kon, N.; Chen, D.; Li, T.; Liu, T.; Jiang, L.; Song, S.; Tavana, O.; Gu, W. ALOX12 Is Required for P53Mediated Tumour Suppression through a Distinct Ferroptosis Pathway. Nat Cell Biol 2019, 21, 579-591, doi:10.1038/s41556-019-0305-6.

127. Zhang, Y.; Qian, Y.; Zhang, J.; Yan, W.; Jung, Y.-S.; Chen, M.; Huang, E.; Lloyd, K.; Duan, Y.; Wang, J.; et al. Ferredoxin Reductase Is Critical for P53-Dependent Tumor Suppression via Iron Regulatory Protein 2. Genes Dev. 2017, doi:10.1101/gad.299388.117.

128. Gao, M.; Monian, P.; Quadri, N.; Ramasamy, R.; Jiang, X. Glutaminolysis and Transferrin Regulate Ferroptosis. Molecular Cell 2015, 59, 298-308, doi:10.1016/j.molcel.2015.06.011.

129. Wang, S.-J.; Li, D.; Ou, Y.; Jiang, L.; Chen, Y.; Zhao, Y.; Gu, W. Acetylation Is Crucial for P53-Mediated Ferroptosis and Tumor Suppression. Cell Reports 2016, 17, 366-373, doi:10.1016/j.celrep.2016.09.022.

130. Xie, Y.; Zhu, S.; Song, X.; Sun, X.; Fan, Y.; Liu, J.; Zhong, M.; Yuan, H.; Zhang, L.; Billiar, T.R.; et al. The Tumor Suppressor P53 Limits Ferroptosis by Blocking DPP4 Activity. Cell Reports 2017, 20, 1692-1704, doi:10.1016/j.celrep.2017.07.055.

131. Tarangelo, A.; Magtanong, L.; Bieging-Rolett, K.T.; Li, Y.; Ye, J.; Attardi, L.D.; Dixon, S.J. P53 Suppresses Metabolic Stress-Induced Ferroptosis in Cancer Cells. Cell Reports 2018, 22, 569-575, doi:10.1016/j.celrep.2017.12.077.

132. Vitale, I.; Galluzzi, L.; Castedo, M.; Kroemer, G. Mitotic Catastrophe: A Mechanism for Avoiding Genomic Instability. Nat Rev Mol Cell Biol 2011, 12, 385-392, doi:10.1038/nrm3115.

133. Vitale, I.; Manic, G.; Castedo, M.; Kroemer, G. Caspase 2 in Mitotic Catastrophe: The Terminator of Aneuploid and Tetraploid Cells. Molecular \& Cellular Oncology 2017, 4, e1299274, doi:10.1080/23723556.2017.1299274.

134. Brown-Suedel, A.N.; Bouchier-Hayes, L. Caspase-2 Substrates: To Apoptosis, Cell Cycle Control, and Beyond. Frontiers in Cell and Developmental Biology 2020, 8, 1662, doi:10.3389/fcell.2020.610022. 
135. Manzl, C.; Krumschnabel, G.; Bock, F.; Sohm, B.; Labi, V.; Baumgartner, F.; Logette, E.; Tschopp, J.; Villunger, A. Caspase-2 Activation in the Absence of PIDDosome Formation. Journal of Cell Biology 2009, 185, 291-303, doi:10.1083/jcb.200811105.

136. Manzl, C.; Peintner, L.; Krumschnabel, G.; Bock, F.; Labi, V.; Drach, M.; Newbold, A.; Johnstone, R.; Villunger, A. PIDDosome-Independent Tumor Suppression by Caspase-2. Cell Death Differ 2012, 19, 1722-1732, doi:10.1038/cdd.2012.54.

137. Tsabar, M.; Mock, C.S.; Venkatachalam, V.; Reyes, J.; Karhohs, K.W.; Oliver, T.G.; Regev, A.; Jambhekar, A.; Lahav, G. A Switch in P53 Dynamics Marks Cells That Escape from DSB-Induced Cell Cycle Arrest. Cell Reports 2020, 32, 107995, doi:10.1016/j.celrep.2020.107995.

138. Ho, L.; Taylor, R.; Dorstyn, L.; Cakouros, D.; Bouillet, P.; Kumar, S. A Tumor Suppressor Function for Caspase2. Proceedings of the National Academy of Sciences of the United States of America 2009, 106, 5336-41, doi:10.1073/pnas.0811928106.

139. Dawar, S.; Lim, Y.; Puccini, J.; White, M.; Thomas, P.; Bouchier-Hayes, L.; Green, D.R.; Dorstyn, L.; Kumar, S. Caspase-2-Mediated Cell Death Is Required for Deleting Aneuploid Cells. Oncogene 2017, 36, 2704-2714, doi:10.1038/onc.2016.423.

140. Dorstyn, L.; Puccini, J.; Wilson, C.H.; Shalini, S.; Nicola, M.; Moore, S.; Kumar, S. Caspase-2 Deficiency Promotes Aberrant DNA-Damage Response and Genetic Instability. Cell Death Differ 2012, 19, 1288-1298, doi:10.1038/cdd.2012.36.

141. Bensaad, K.; Vousden, K.H. P53: New Roles in Metabolism. Trends in Cell Biology 2007, 17, 286-291, doi:10.1016/j.tcb.2007.04.004.

142. Stewart-Ornstein, J.; Iwamoto, Y.; Miller, M.A.; Prytyskach, M.A.; Ferretti, S.; Holzer, P.; Kallen, J.; Furet, P.; Jambhekar, A.; Forrester, W.C.; et al. P53 Dynamics Vary between Tissues and Are Linked with Radiation Sensitivity. Nat Commun 2021, 12, 898, doi:10.1038/s41467-021-21145-z.

143. Tovar, C.; Rosinski, J.; Filipovic, Z.; Higgins, B.; Kolinsky, K.; Hilton, H.; Zhao, X.; Vu, B.T.; Qing, W.; Packman, K.; et al. Small-Molecule MDM2 Antagonists Reveal Aberrant P53 Signaling in Cancer: Implications for Therapy. PNAS 2006, 103, 1888-1893, doi:10.1073/pnas.0507493103.

144. Lahav, G.; Rosenfeld, N.; Sigal, A.; Geva-Zatorsky, N.; Levine, A.J.; Elowitz, M.B.; Alon, U. Dynamics of the P53-Mdm2 Feedback Loop in Individual Cells. Nat Genet 2004, 36, 147-150, doi:10.1038/ng1293.

145. Purvis, J.E.; Karhohs, K.W.; Mock, C.; Batchelor, E.; Loewer, A.; Lahav, G. P53 Dynamics Control Cell Fate. Science 2012, 336, 1440-1444, doi:10.1126/science.1218351.

146. Kracikova, M.; Akiri, G.; George, A.; Sachidanandam, R.; Aaronson, S.A. A Threshold Mechanism Mediates P53 Cell Fate Decision between Growth Arrest and Apoptosis. Cell Death Differ 2013, 20, 576-588, doi:10.1038/cdd.2012.155.

147. Paek, A.L.; Liu, J.C.; Loewer, A.; Forrester, W.C.; Lahav, G. Cell-to-Cell Variation in P53 Dynamics Leads to Fractional Killing. Cell 2016, 165, 631-642, doi:10.1016/j.cell.2016.03.025.

148. Hafner, A.; Stewart-Ornstein, J.; Purvis, J.E.; Forrester, W.C.; Bulyk, M.L.; Lahav, G. P53 Pulses Lead to Distinct Patterns of Gene Expression Albeit Similar DNA-Binding Dynamics. Nat Struct Mol Biol 2017, 24, 840-847, doi:10.1038/nsmb.3452.

149. Rizzotto, D.; Zaccara, S.; Rossi, A.; Galbraith, M.D.; Andrysik, Z.; Pandey, A.; Sullivan, K.D.; Quattrone, A.; Espinosa, J.M.; Dassi, E.; et al. Nutlin-Induced Apoptosis Is Specified by a Translation Program Regulated by PCBP2 and DHX30. Cell Reports 2020, 30, 4355-4369.e6, doi:10.1016/j.celrep.2020.03.011.

150. Freeman, J.A.; Espinosa, J.M. The Impact of Post-Transcriptional Regulation in the P53 Network. Briefings in Functional Genomics 2013, 12, 46-57, doi:10.1093/bfgp/els058.

151. Zaccara, S.; Tebaldi, T.; Pederiva, C.; Ciribilli, Y.; Bisio, A.; Inga, A. P53-Directed Translational Control Can Shape and Expand the Universe of P53 Target Genes. Cell Death Differ 2014, 21, 1522-1534, doi:10.1038/cdd.2014.79. 